\title{
Attention deficit hyperactive disorder- As a determinant of learning disability
}

\author{
JATINDER K. GULATI, NEHA LAKHANPAL AND JASVINDER KAUR
}

Received: 27.04.2015; Revised: 30.04.2015; Accepted: 20.05.2015

See end of the paper for authors' affiliations

\section{JATINDER K. GULATI}

Department of Human

Development, Punjab Agricultural

University, LUDHIANA (PUNJAB)

INDIA
ABSTRACT : Children with ADHD have been found to have weaknesses with their working memory leading to difficulty with problems involving the manipulation of verbal and non-verbal information that way effecting their learning processes (Martinussen et al., 2006). This study was aimed to find the role of Attention Deficit Hyperactive Disorder (ADHD) as one of the determinant for learning disabilities among primary school children. A methodical process was followed for drawing the sample that comprised of 120 first and second grade children. The sample was equally divided into learning disabled $(n=60)$ and learning abled $(n=60)$ children. The results of the present study have highlighted the role of learning disabilities, displayed a higher degree of attention deficit disorders. They were more impulsive, hyperactive, day dreamers and were having poor concentration.

KEY WORDS: Learning disabilities, Attention deficit hyperactive disorder, Reading-writing skills, Primary school children

- HOW TO CITE THIS PAPER : Gulati, Jatinder K., Lakhanpal, Neha and Kaur, Jasvinder (2015). Attention deficit hyperactive disorder - As a determinant of learning disability. Asian J. Home Sci., 10 (1) : 196-202. 